\title{
On the nature of ULF wave power during nightside auroral activations and substorms: 2. temporal evolution
}

Article

Published Version

Rae, I. J., Murphy, K. R., Watt, C. E. J. and Mann, I. R. (2011) On the nature of ULF wave power during nightside auroral activations and substorms: 2 . temporal evolution. Journal of Geophysical Research, 116. A00I22. ISSN 0148-0227 doi: https://doi.org/10.1029/2010JA015762 Available at https://centaur.reading.ac.uk/32807/

It is advisable to refer to the publisher's version if you intend to cite from the work. See Guidance on citing.

Published version at: http://dx.doi.org/10.1029/2010JA015762

To link to this article DOI: http://dx.doi.org/10.1029/2010JA015762

Publisher: American Geophysical Union

All outputs in CentAUR are protected by Intellectual Property Rights law, including copyright law. Copyright and IPR is retained by the creators or other copyright holders. Terms and conditions for use of this material are defined in the End User Agreement.

www.reading.ac.uk/centaur 
Central Archive at the University of Reading

Reading's research outputs online 


\title{
On the nature of ULF wave power during nightside auroral activations and substorms:
}

\section{Temporal evolution}

\author{
I. J. Rae, ${ }^{1}$ K. R. Murphy, ${ }^{1}$ C. E. J. Watt, ${ }^{1}$ and I. R. Mann ${ }^{1}$ \\ Received 31 May 2010; accepted 13 September 2010; published 26 January 2011.
}

[1] We present a statistical analysis of the time evolution of ground magnetic fluctuations in three (12-48 s, 24-96 s and 48-192 s) period bands during nightside auroral activations. We use an independently derived auroral activation list composed of both substorms and pseudo-breakups to provide an estimate of the activation times of nightside aurora during periods with comprehensive ground magnetometer coverage. One hundred eightyone events in total are studied to demonstrate the statistical nature of the time evolution of magnetic wave power during the $\sim 30$ min surrounding auroral activations. We find that the magnetic wave power is approximately constant before an auroral activation, starts to grow up to $90 \mathrm{~s}$ prior to the optical onset time, maximizes a few minutes after the auroral activation, then decays slightly to a new, and higher, constant level. Importantly, magnetic ULF wave power always remains elevated after an auroral activation, whether it is a substorm or a pseudo-breakup. We subsequently divide the auroral activation list into events that formed part of ongoing auroral activity and events that had little preceding geomagnetic activity. We find that the evolution of wave power in the $\sim 10-200$ s period band essentially behaves in the same manner through auroral onset, regardless of event type. The absolute power across ULF wave bands, however, displays a power law-like dependency throughout a $30 \mathrm{~min}$ period centered on auroral onset time. We also find evidence of a secondary maximum in wave power at high latitudes $\sim 10$ min following isolated substorm activations. Most significantly, we demonstrate that magnetic wave power levels persist after auroral activations for $\sim 10 \mathrm{~min}$, which is consistent with recent findings of wave-driven auroral precipitation during substorms. This suggests that magnetic wave power and auroral particle precipitation are intimately linked and key components of the substorm onset process.

Citation: Rae, I. J., K. R. Murphy, C. E. J. Watt, and I. R. Mann (2011), On the nature of ULF wave power during nightside auroral activations and substorms: 2. Temporal evolution, J. Geophys. Res., 116, A00I22, doi:10.1029/2010JA015762.

\section{Introduction}

[2] The link between the optical intensification of the most equatorward auroral arc and a sharp magnetic bay during substorm expansion phase has been studied for well over half a century [e.g., Heppner, 1958; Akasofu, 1964]. However, determining the physics of the energy release during the initiation of the substorm expansion phase has remained elusive to the current day [e.g., Lui, 2004, Angelopoulos, 2008; Angelopoulos et al., 2008a, 2008b; Lui, 2009; Angelopoulos et al., 2009]. The primary difficulty arises due to the ambiguity in the temporal sequence of events during substorms, both in space and in the ionosphere. Two phenomenological models are typically invoked to explain substorm initiation and energy release: via magnetic reconnection at the Near-Earth Neutral Line (commonly referred

\footnotetext{
${ }^{1}$ Department of Physics, University of Alberta, Edmonton, Alberta, Canada.

Copyright 2011 by the American Geophysical Union. 0148-0227/11/2010JA015762
}

to as NENL [e.g., Hones, 1976]) or via explosive growth of a plasma instability in the nearer magnetotail [e.g., Roux et al., 1991; Lui et al., 1991, Voronkov et al., 1997; Horton et al., 2001; Cheng, 2004]. However, a number of other phenomenological models have also been proposed to explain the initiation of energy release during expansion phase onset (e.g., Boundary Layer Dynamics model [Rostoker and Eastman, 1987], Near Geophysical Onset [e.g., Maynard et al., 1996a, 1996b], and Global Alfvénic Interaction [Song and Lysak, 2001]). Recently, Nishimura et al. [2010] proposed a modified substorm onset scenario whereby substorm onset was preceded by enhanced earthward plasma transport from NENL reconnection sufficient to destabilize the inner magnetosphere and cause the onset of the expansion phase. In their scenario, these authors proposed a repeatable sequence of events simply from ionospheric measurements that occurs in the following way: (1) a poleward boundary intensification (PBI) [Elphinstone et al., 1995] occurs at, or close to, the poleward boundary of the auroral oval $\sim$ minutes prior to auroral onset; this is interpreted as clear evidence of reconnection close to the NENL; (2) an equatorward-moving 
north-south (and/or east-west) aligned arc moving toward the subsequent onset region; this is interpreted as evidence of enhanced earthward plasma flow and flux transport [e.g., Walsh et al., 2009]; and (3) onset occurs on the most equatorward auroral arc at $\mathrm{t}_{0}$.

[3] These authors compiled a list of 251 auroral intensification events, the majority of which are found to satisfy at least points 1 and 3 . In this paper, we use this list of independently determined auroral intensification events to study the evolution of Ultra Low Frequency (ULF) wave power at the location of auroral onset and at locations at both higher and lower latitudes. By using this independent list, we aim to minimize any subjective event selection, and prevent any bias from influencing the results of this study. Note that the only source of timing uncertainty implied in the Nishimura list is the $3 \mathrm{~s}$ cadence of the THEMIS ASI.

[4] ULF waves have been shown to play a pivotal role in determining the onset time and location of substorm expansion phase onset. Previous studies often concentrated on distinct ULF wave bands as identified by Jacobs et al. [1964], such as the Pi2 (40-150 s period [e.g., Olson and Rostoker, 1975; Southwood and Hughes, 1985; Samson, 1985] and see reviews by Baumjohann and Glassmeier [1984], Olson [1999] and Keiling [2009]) and Pil (1-40 s period [e.g., Bösinger and Yahnin, 1987; Arnoldy et al., 1987; Bösinger, 1989; Arnoldy et al., 1998; Lessard et al., 2006; Posch et al., 2007]). Both ULF wave bands have been shown to provide important information on the specifics during expansion phase onset. For example, Pi2s can be used to define the substorm current wedge location [e.g., McPherron et al., 1973; Lester et al., 1983], the location of the auroral surge [e.g., Gelpi et al., 1987] and low-latitude Pi2s can be used to determine the meridian of auroral onset [e.g., Takahashi and Liou, 2004] while auroral zone Pi1B waves [e.g., Bösinger and Yahnin, 1987; Arnoldy et al., 1987; Bösinger, 1989] have been used to accurately locate the specific region of auroral substorm onset. However, it is only through the analysis of the entire ULF wave spectrum that the most important physics are now being extracted. Specifically, through probing the entire ULF wave spectrum, recent work has discovered that a ULF wave band that overlaps both the Jacobs et al. [1964] defined Pi1 and Pi2 ULF wave bands (hereafter referred to as Pi1-2 waves) is often the critical frequency band for observing the first moments of substorm expansion phase onset in the ionosphere [e.g., Milling et al., 2008; Mann et al., 2008; Murphy et al., 2009a, 2009b; Rae et al., 2009a, 2009b, 2010]. Indeed, Jacobs et al. [1964] noted that "Usually the period of Pi1 is quite small, seldom exceeding $20 \mathrm{sec} . .$. In any decisions on classification, some compromise is inevitable. Since the physical processes involved are not well understood, it is pointless to introduce a highly sophisticated scheme," hence Pi1-2 ULF waves of 24-96 s period represent short-period Pi2 waves in their general classification scheme. This subtlety has been often overlooked in the somewhat rigid classification scheme currently adopted by the substorm community from the conclusions of the Jacobs et al. [1964] study, and suggests that the full range of ULF wave periods should be included in any study of substorm dynamics.

[5] In these more recent papers, Milling et al. [2008] presented clear evidence of a ULF wave epicenter in the onset of Pi1-2 ULF waves during substorm onset. Murphy et al. [2009a] demonstrated that this epicenter of wave onset was a repeatable phenomena that occurred prior to largescale auroral intensification of auroral breakup as identified by a global imager. Liou and Zhang [2009] noted that Murphy et al. [2009a] did not consider the 2 min cadence of the instrument when concluding that ULF wave onset preceded the global intensification recorded by the global auroral imager. However, Murphy et al. [2009b] countered that even when including this 2 min uncertainty, ULF wave onset preceded any global auroral intensification as recorded by a global auroral imager, and indeed prior to a more local estimate of auroral onset using a meridian scanning photometer. Murphy et al. [2009b] demonstrated that the conclusions of Murphy et al. [2009a] were valid for all but one event, and this event included a global auroral imaging data gap. Murphy et al. [2009b] then conclude that "it is likely that global satellite imagers do not have the sensitivity or resolution to record the initial dynamics or formation of an individual quiet discrete arc." In complementary work, Rae et al. [2009a, 2009b] studied the onset of Pi1-2 ULF waves relative to the THEMIS All-Sky Image (ASI) local auroral measurements, instruments which could provide sufficient temporal and spatial resolution to probe the precise optical and magnetic onset in two dimensions but in white light only. Interestingly, Rae et al. [2009a, 2009b] show that the onset epicenter of Pi1-2 ULF waves could identify both the location and time of the first signature of expansion phase onset observed in the ionosphere to within an error of $\sim 10 \mathrm{~s}$; this Pi1-2 magnetic epicenter being observed at the same time and in the same location as the first optical fluctuations along the onset arc $\sim$ minutes prior to auroral breakup. Presumably auroral breakup therefore corresponds closer to the auroral onset time as observed by global imaging. The overwhelming conclusions of these papers are that Pi1-2 ULF waves can be used to define the location and time of the first ionospheric signatures of substorm expansion phase onset, and that the signature of global auroral intensification using a global imager typically occurs $\sim$ minutes later.

[6] However, these results are all isolated case studies of substorms and pseudo-breakups and may not represent a statistically significant portion of all substorm onsets or nightside auroral activations. In a companion paper, Murphy et al. [2011] (hereafter referred to as Paper 1) present a statistical study of the properties of the ULF wave spectrum in three bands (10-40 s period Pi1*, denoted as such since the entire Pil spectrum of $1-40 \mathrm{~s}$ is not considered in Paper 1 or within this manuscript, 24-96 s period Pi1-2 and 40-150 s period Pi2) in order to determine whether there is a statistical difference between the spatial properties of each ULF wave band. The results in Paper 1 are obtained using 40 min time intervals centered on the global auroral intensification times determined by Frey et al. [2004] and Frey and Mende [2007], and Fourier analysis of the ULF wave characteristics in these three bands. The results in Paper 1 show that there are some statistical differences in the spatial distributions of $\mathrm{Pi}{ }^{*}$ and $\mathrm{Pi} 1-2$ and $\mathrm{Pi} 2$ waves. For $\mathrm{Pi}{ }^{*}$ wave power to be observed at the same distances from the location of auroral intensification, a large $\mathrm{AE}$ is required in excess of $\sim 600$ nT. While Pi1-2 and Pi2 waves demonstrate the same polarization profiles as noted by Gelpi et al. [1987] and Lester et al. [1983], Pi1* waves appear to be more featureless, potentially due to their broadband nature as noted 


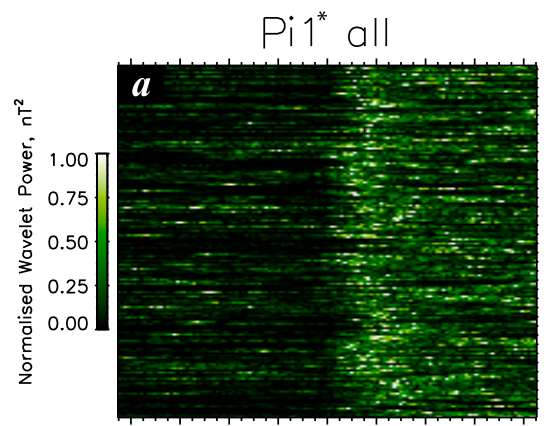

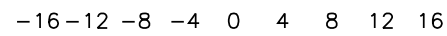

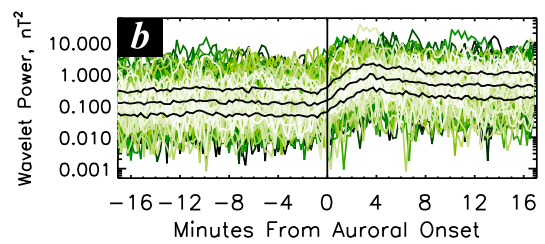

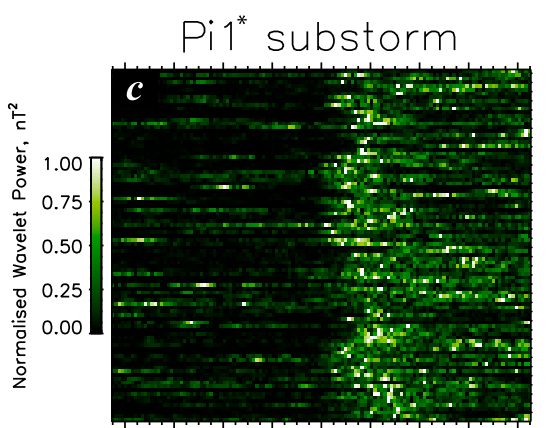

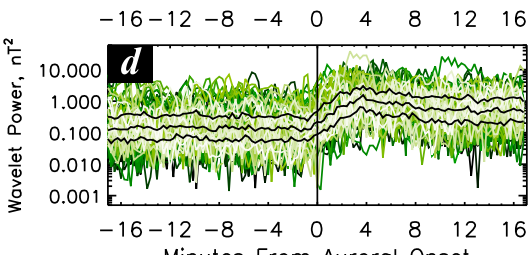

Minutes From Auroral Onset
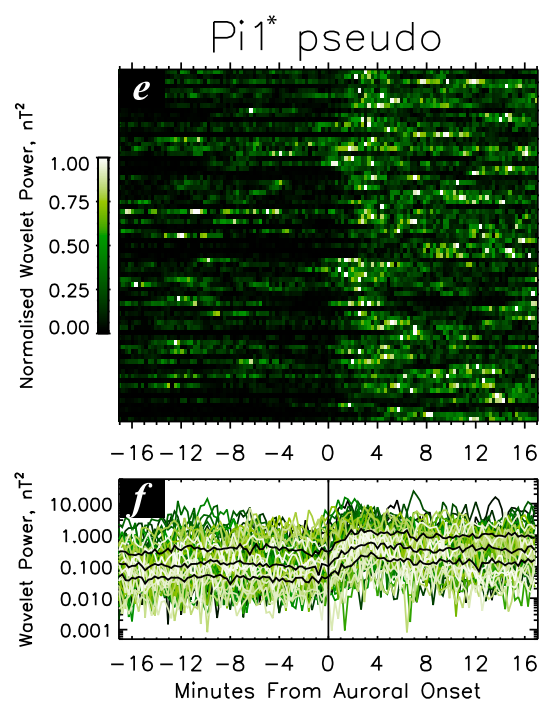

Figure 1. A superposed epoch analysis of the Pi1* ULF wave activity during the auroral activations in the Nishimura list [Nishimura et al., 2010]. Figure 1a shows the normalized ULF wave activity in the Pi1* (12-48 s) period band as a function of time for each individual event. Figure $1 \mathrm{~b}$ shows the Pi1* wave power for all events as a function of time together with the median, upper and lower quartiles. Figure 1c shows all substorm events from the Nishimura list in the same format as Figure 1a, and Figure 1d shows the Pi1* power during substorms in the same format as Figure 1d. Figures 1e and $1 \mathrm{f}$ show the equivalent Pi1* normalized and median wave power for pseudo-breakups, respectively.

by Posch et al. [2007] or being temporally localized in the window studied. More importantly, it is shown that the ULF wave power spectra for a 40 min interval surrounding substorm onset is characteristic of a power law, which suggests that statistically no particular wave band dominates the spectrum during substorm expansion phase onset.

[7] In this companion paper, we focus on the temporal evolution of ULF wave power during the period before and after sudden auroral intensification. The list of 251 auroral intensification events identified by Nishimura et al. [2010] is used to independently determine the time and location of auroral activity. Since the Nishimura list contains both substorms and pseudo-breakups, we determine the temporal characteristics of ULF waves during both types of auroral events. We also split the event list into events that were preceded by significant geomagnetic activity and those that were not (defined as compound and isolated events, respectively, though note that using the definitions isolated and compound does not refer to any activity following $\mathrm{t}_{0}$ ). Section 2 gives details of the data set used to obtain these results, and our analysis techniques. In section 3 , we discuss the evolution of ULF wave power in the immediate vicinity of the auroral intensification site, whereas the results presented in section 4 extend this analysis to stations both poleward and equatorward of the initial auroral activation. We present discussion of the results in section 5 and our conclusions in section 6 .

\section{Methodology}

[8] In this paper, we use $1 \mathrm{~s}$ cadence ground magnetometer data from the North American sector, which includes the CARISMA [Mann et al., 2008] and THEMIS GBO [Russell et al., 2008] and EPO [Peticolas et al., 2008], GIMA and CANMOS magnetometer chains. We use the times and locations of the onset of auroral activity as defined in the Nishimura list [Nishimura et al., 2010] to statistically investigate the magnetic activity associated with sudden auroral activation. We calculate the wavelet power in the Pi1* (12-48 s period), Pi1-2 (24-96 s period) and Pi2 (48192 s period) ULF wave bands using the Automated Wavelet Estimation of Substorm Onset and Magnetic Events (AWESOME) [Murphy et al., 2009a] algorithm for the magnetometer that is colocated with the camera that recorded the auroral activation. Any magnetometer time series that encompassed a data gap or spike during the period of interest was discarded from the statistics. Thus 167 events out of a possible 251 had usable data at the onset latitude. Where we extend the analysis to ULF wave power at higher and lower latitudes, we were able to increase the number of usable events to 181 . Each analyzed time series is $2^{11}$ seconds in length, corresponding to $\pm 16 \min \left(2^{10}\right.$ points $)$ on either side of the onset time $t_{0}$ as defined in the Nishimura list. As previously mentioned, Nishimura et al. [2010] also further determine which of their 251 events demonstrate poleward expansion of the aurora in order to distinguish between substorms and pseudo-breakups, and so we subcategorize this event list into substorms and pseudobreakups according to this classification. First, we focus on the evolution of ULF wave power at the identified onset location and subsequently, we investigate the temporal variation of magnetic activity at varying distances from the defined Nishimura onset location. A total of 944 magnetometer intervals are analyzed in this study.

\section{ULF Waves in the Vicinity of the Auroral Activation Region}

[9] Figure 1 shows a superposed epoch analysis of the Pi1* ULF wave activity during the auroral activations in the 

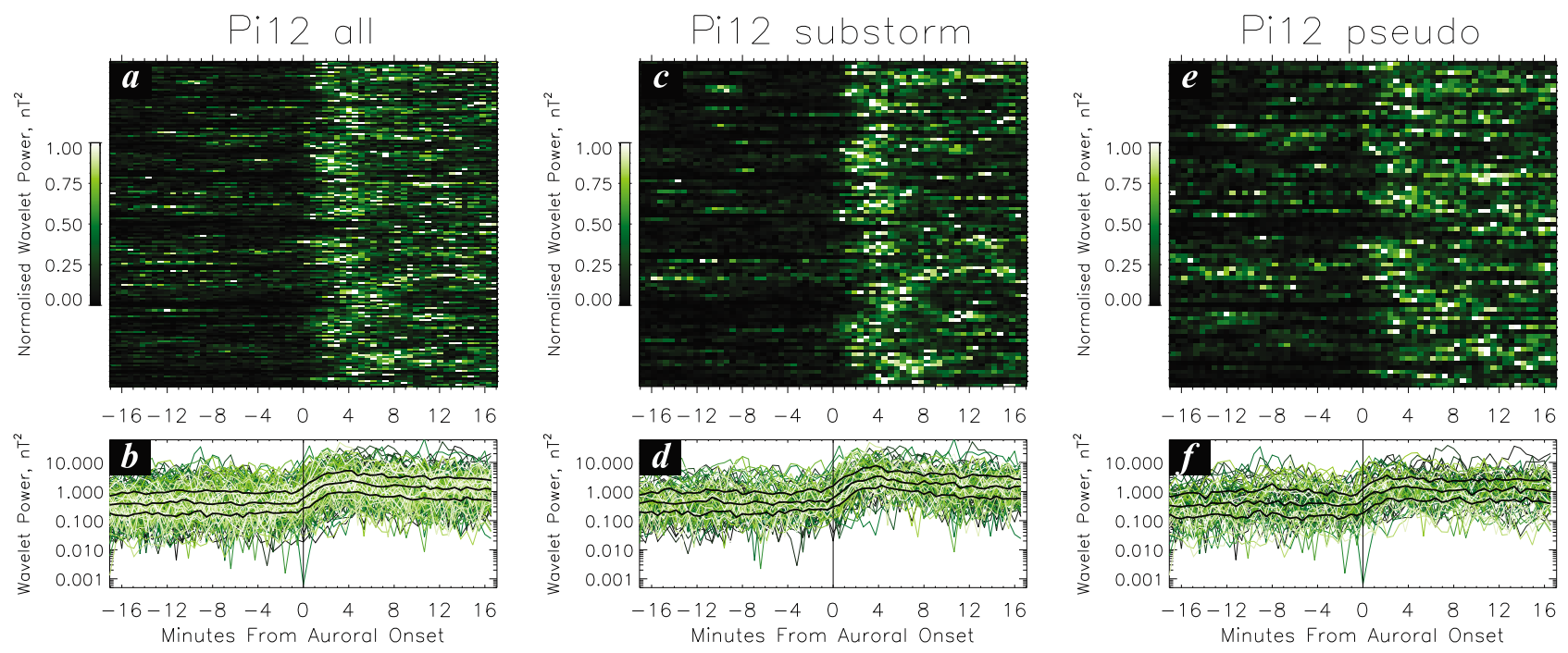

Figure 2. A superposed epoch analysis of the Pi1-2 (24-96 s period) ULF wave activity during the auroral activations in the Nishimura list [Nishimura et al., 2010] in the same format as Figure 1.

Nishimura list from the magnetometer station closest to each identified onset location. The top panels show the normalized ULF wave activity as a function of epoch time for each individual event. Figure 1a shows all 167 events used in this study, whereas Figures 1c and 1e show the subset of substorms and pseudo-breakups, respectively, as identified by Nishimura et al. [2010]. In Figures 1a, 1c, and 1e, black represents minimum ULF wave power, while white represents maximum ULF wave power. In general, the maximum in Pi1* ULF wave power occurs after $\mathrm{t}_{0}$. Interestingly, Figure 1a shows that there are some events (primarily contained within the middle of Figure 1a) that have a maximum in Pi1* power between 16 and 2 min prior to $t_{0}$, though the majority of Pi1* maxima occur after $t_{0}$. By comparing Figure $1 \mathrm{c}$ to $1 \mathrm{e}$, it is clear that almost all substorm events clearly show more Pi1* wave power after the auroral activation (mainly dark colors for $t<t_{0}$ ). On the other hand, there are more pseudobreakup events than substorm events which show significant Pi1* wave power prior to the auroral activation (i.e., there is more of the light colors in the time $t<t_{0}$ in Figure 1e than in Figure 1c).

[10] The bottom panels in Figure 1 show the actual Pi1* wave power as a function of time, together with the median, upper and lower quartiles. The lower panels are not normalized. Figure $1 \mathrm{~b}$ shows all 167 events, and Figures $1 \mathrm{~d}$ and 1f show the subsets of substorms and pseudo-breakups, respectively. It is clear from Figure $1 \mathrm{~b}$ that statistically, the Pi1* wave power at the auroral activation location undergoes essentially the same evolution during each type of event. Pi1* wave power starts at a relatively constant level, then starts to increase $\sim 1 \mathrm{~min}$ before $t_{0}$. The power continues to increase through the beginning of the auroral activation, and reaches a maximum roughly four minutes after $t_{0}$. After this, there is a slight decrease in power, but for $t_{0}+8 \mathrm{~min}$ to the end of the interval, the power remains roughly constant at a level which is higher than the power level observed before the auroral activation. The subset of substorm events (Figure 1d) displays similar Pi1* power characteristics to those displayed for all events. On the other hand, the Pi1* power during pseudo-breakups increases for a shorter time (from $t_{0}-1 \mathrm{~min}$ to $t_{0}+3 \mathrm{~min}$ ) and the level of Pi1* power after auroral activation is smaller for pseudo-breakups than it is for substorms.

[11] Figure 2 shows the results for the Pil-2 ULF wave band (24-96 s period) in the same format as Figure 1 . Figures 2a, 2c, and 2e show the same trends as their equivalent panels in Figure 1, namely that the difference between Pil-2 wave power before and after auroral activation is more pronounced for substorms than it is for pseudobreakups. Figures $2 \mathrm{~b}, 2 \mathrm{~d}$, and $2 \mathrm{f}$ also demonstrate similar characteristics as their equivalent panels in Figure 1. The Pi1-2 wave power starts at a roughly constant level, starts growing $\sim 1$ min before the auroral activation time and peaks $\sim 4$ min after the activation time, before returning to another roughly constant level which is higher than that at the beginning of the interval. The growth time of Pil-2 waves during pseudo-breakups is shorter than it is during substorms, and the resulting wave power is typically smaller.

[12] Figure 3 shows the results for the Pi2 ULF wave band (48-192 s period) in the same format as Figure 1. Again, the change in ULF wave power during auroral activation is more pronounced for substorms than for pseudo-breakups as there are more of the lighter colors prior to $t_{0}$ in Figure $3 \mathrm{e}$ than in Figure 3c. Interestingly the increase in Pi2 power during substorms seems to start earlier than the increases in Pi1* and Pi1-2 power seen in Figure 1d and Figure 2d, possibly up to four minutes before $t_{0}$. The pseudo-breakup $\mathrm{Pi} 2$ power (Figure $3 \mathrm{f}$ ) increases later than the substorm Pi2 power (Figure 3d).

[13] We summarize the information in Figures 1, 2 and 3 in Figure 4 in order to quantify the levels of ULF wave power and times of maximum amplitude during auroral activations. Figure 4 shows the time variation of the median (red), and upper and lower quartile (blue) power in each ULF wave band for (a) all events, (b) substorms, and (c) pseudobreakups. The absolute values of wave power increase with wave period, as demonstrated in Paper 1. However, there are no obvious differences in the evolution of ULF wave power 

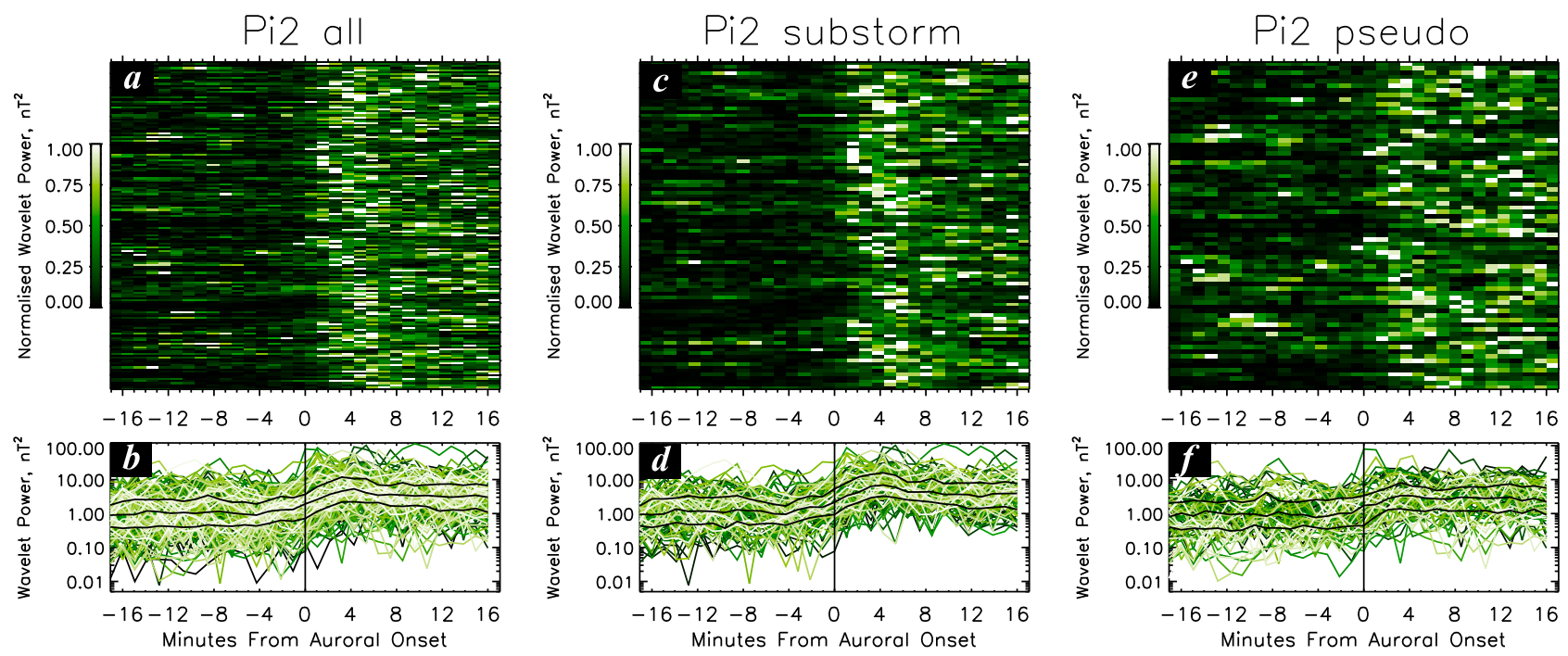

Figure 3. A superposed epoch analysis of the Pi2 (48-192 s period) ULF wave activity during the auroral activations in the Nishimura list [Nishimura et al., 2010] in the same format as Figure 1.

in the different wave bands, or in fact between wave power evolution during the different types of event, whether they are substorms or pseudo-breakups. The characteristic power levels and growth times are summarized in Table 1. The growth phase power is calculated from the average median power in the period $t_{0}-16 \mathrm{~min}$ to $t_{0}-8 \mathrm{~min}$. The recovery phase power is calculated from the average median power in the period $t_{0}+8 \mathrm{~min}$ to $t_{0}+16 \mathrm{~min}$. These intervals are chosen in order to avoid periods that are close to $t_{0}$, as these contain changes in ULF wave power associated with onset, as shown in Figure 4. For each wave band, the recovery phase power is slightly higher in substorms as compared to pseudo-breakups.

\section{ULF Waves at a Distance From the Auroral Activation Region}

[14] In this section, we investigate the evolution of ULF wave activity at higher and lower latitudes prior to the ULF wave growth seen in the auroral activation region. We select magnetometers that lie within $\pm 20^{\circ}$ longitude of the station that observed onset, and determine their relative location in latitude to the onset station for the events identified in the Nishimura list. The $\pm 20^{\circ}$ longitudinal bin is a compromise in order to obtain sufficient magnetometer coverage at high latitudes while retaining a narrow enough region such that only latitudinal variations are primarily visible in our analysis. We further categorize events in the Nishimura list into those that were preceded by significant geomagnetic activity and those that were not, based upon THEMIS AE measurements. Events that were preceded by IALI values that were in excess of $100 \mathrm{nT}$ during the $30 \mathrm{~min}$ prior to the defined auroral onset are classified as compound events, and events that were not are classified as isolated events. The calculation of a quiet time curve from the THEMIS GMAG data can leave a residual level of $\sim$ tens $\mathrm{nT}$ in the auroral indices calculation and so our choice of $100 \mathrm{nT}$ as a demarcation between "quiet" and "active" events should not be affected by these residual values.
[15] Figure 5 shows a summary of the normalized wave power as a function of epoch time $t_{0}$, for all substorms and pseudo-breakups and for isolated and compound events for the three ULF wave bands discussed previously as a function of latitude away from auroral onset. Each set of three vertical panels shows ULF wave power for stations above the onset latitude (upper panel), at the onset latitude (middle panel), and below the onset latitude (lower panel). The "Above onset" panels and "Below onset" panels are ordered with increasing distance away from the onset location, but have not been binned by latitude. There are a number of interesting trends shown in Figure 5.

[16] In general, for all Events (Figures 5a, 5d, and 5g): (1) An increase in Pi1* wave power is not generally observed at lowest latitudes at any time during the period surrounding auroral activation (Figure 5a). An increase in Pi1-2 ULF wave power is not generally observed at low latitudes for pseudo-breakups (Figure 5d). (2) More ULF wave activity is observed prior to onset in pseudo-breakups rather than substorms (Figures 5a-5i). This is observed at all latitudes. (3) The largest amplitude ULF waves occur after $t_{0}$. For Isolated Events $(\mid \mathrm{ALI}<100 \mathrm{nT})$. (4) The majority of events show a lack of ULF wave power prior to $t_{0}$ for substorms other than at very high latitudes, in contrast to pseudo-breakups where significant power can exist prior to $t_{0}$ at all latitudes.

[17] In general, the differences between Isolated (Figures 5b, $5 \mathrm{e}$, and 5h) and Compound (Figures 5c, 5f, and 5i) events are that the compound events have more relative ULF wave power prior to $t_{0}$, and that pseudo-breakups have more relative ULF wave power prior to $t_{0}$ as compared to substorms. Therefore, the class of events that show the largest relative ULF wave power relative to onset (or equivalently the smallest change in ULF wave power after $t_{0}$ ) are compound pseudo-breakups. On the other hand, isolated substorms show the largest change in ULF wave power through $t_{0}$.

[18] There appears to be some evidence of a high-latitude $\mathrm{Pi} 2$ signature in both isolated and compound substorms prior to $t_{0}$ (Figures $5 \mathrm{~h}$ and $5 \mathrm{i}$ ), which may also be apparent 
in the Pi1-2 ULF wave band in the isolated case (Figure 5e). This behavior will be more fully investigated in future studies. Finally, it is interesting to note that out of the subset of Nishimura list events studied in this paper reveal, the vast
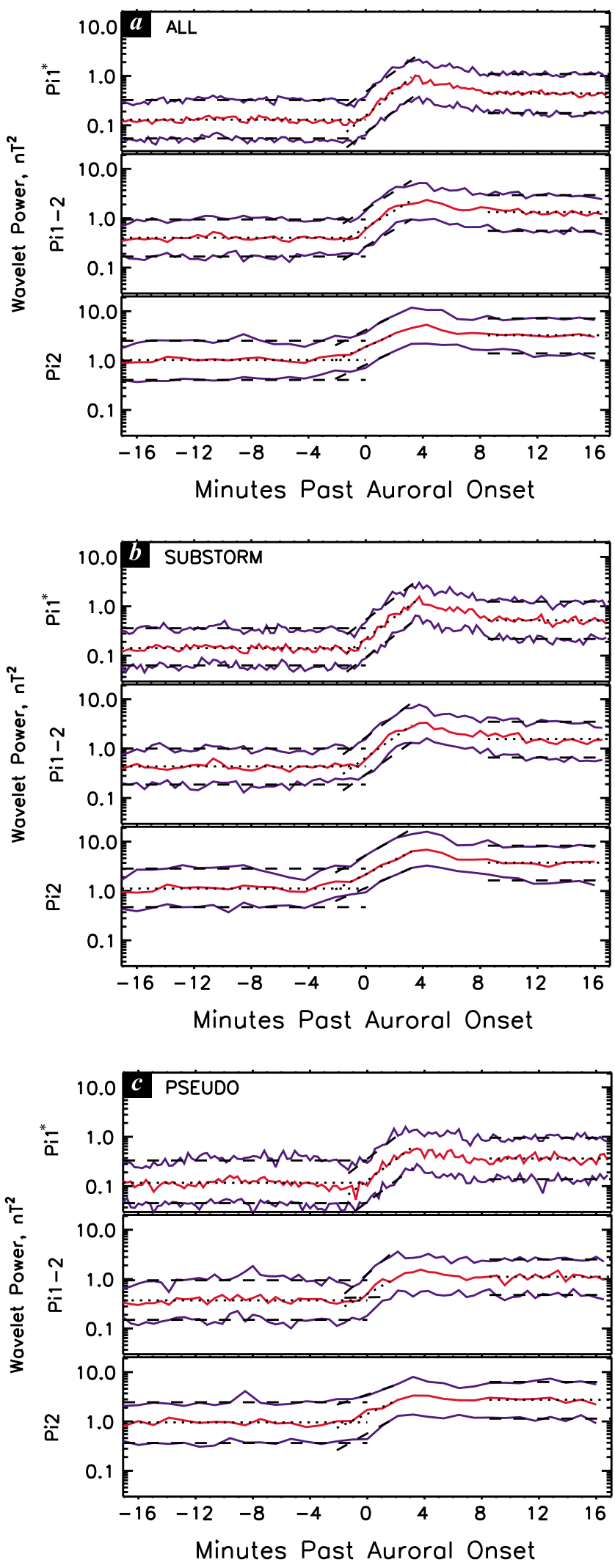

majority satisfy the "compound event" criteria we have used in this study. Isolated substorms do not appear to be the norm within this nightside auroral activation list.

[19] Figure 6 shows the median ULF wave power in each ULF wave band for substorms (red lines) and pseudobreakups (blue lines) for all events (left) and for isolated (middle) and compound (right) events. Figure 6 confirms the results shown in Figure 5, that the increase in ULF wave power during substorms (red trace) is larger than the increase in ULF wave power during pseudo-breakups (blue trace). The initial median wave power for all wave bands and for all events appears to be smaller at the low-latitude stations than it is at the onset latitude and at higher latitudes. The median ULF power increases in all events and at all latitudes except for Pi1* power at low latitudes during pseudo-breakups, as expected from the lower panels of Figures 5a, 5b and 5c. At high latitudes, the ULF wave power in all three wave bands for isolated substorms does not settle to a roughly constant level after $t_{0}$, but fluctuates significantly, with a secondary peak occurring at $\sim t_{0}+12 \mathrm{~min}$. This may be due to subsequent intensifications of the auroral surge at high latitudes and/or PBI activity that are known to occur $\sim$ minutes after onset [e.g., Lyons et al., 1999]. Note that this subset of events is the smallest in the entire analysis, with only 13 magnetometer intervals occurring at high latitudes during isolated substorms. Further analysis is required in order to discover whether this trend is statistically significant.

[20] Interestingly, the level of ULF wave power prior to onset in compound substorms and pseudo-breakups is as large as the level of ULF wave power following onset in isolated substorms and pseudo-breakups. This is observed across all ULF wave bands and at all latitudes. This is perhaps a not entirely unexpected result since during isolated events, there is little magnetic fluctuation prior to onset, while in compound events IALI is larger than $100 \mathrm{nT}$ and there is by definition magnetic activity prior to $t_{0}$ which would mean that the background ULF wave levels (the recovery phase power identified in Table 1) may not have subsided from previous activations.

\section{Discussion}

[21] Ultra Low Frequency magnetic waves have been closely associated with both the initiation and the subsequent consequences of substorm expansion phase onset. Historically however, the "two minute problem" [Ohtani, 2004] has posed a significant quandary for observational studies since it is difficult to resolve the onset of a nonlinear process via visual inspection of a ground magnetometer time series. The onset of an increase in auroral intensity is also fraught with the same problem; namely, where does growth in optical intensities start?

Figure 4. Median, upper, and lower quartile time variation of (top) Pi1*, (middle) Pi1-2, and (bottom) Pi2 ULF wave power for (a) all events, (b) substorms, and (c) pseudobreakups. Overplotted are the lines of best fit to the growth and recovery phases and a line of nest fit between the location where the ULF wave power rises above the growth phase value and the maximum amplitudes (see Table 1 for details). 
Table 1. The Characteristic Preactivation and Postactivation Power Levels and Growth Times ${ }^{\mathrm{a}}$

\begin{tabular}{lcccc}
\hline $\begin{array}{c}\text { ULF Wave } \\
\text { Band }\end{array}$ & $\begin{array}{c}\text { Growth Phase } \\
\text { Power }\left(\mathrm{nT}^{2}\right)\end{array}$ & $\begin{array}{c}\text { Recovery Phase } \\
\text { Power }\left(\mathrm{nT}^{2}\right)\end{array}$ & $\begin{array}{c}\text { Max Power } \\
\left(\mathrm{nT}^{2}\right)\end{array}$ & $\begin{array}{c}\text { Time of } \\
\text { Max Power }(\mathrm{s})\end{array}$ \\
\hline \multicolumn{5}{c}{ All Events } \\
Pi1* & 0.13 & 0.44 & 1.02 & 216.00 \\
Pi1-2 & 0.41 & 1.33 & 2.36 & 272.00 \\
Pi2 & 1.02 & 3.26 & 5.34 & 288.00 \\
& \multicolumn{4}{c}{ Substorms } \\
Pi1* & 0.14 & 0.52 & 1.57 & 232.00 \\
Pi1-2 & 0.44 & 1.57 & 3.34 & 272.00 \\
Pi2 & 1.10 & 3.75 & 6.88 & 288.00 \\
& \multicolumn{4}{c}{ Pseudo-Breakups } \\
Pi1* & 0.12 & 0.36 & 0.58 & 216.00 \\
Pi1-2 & 0.37 & 1.11 & 1.57 & 240.00 \\
Pi2 & 0.97 & 2.75 & 3.35 & 224.00 \\
\hline
\end{tabular}

${ }^{\mathrm{a}}$ The growth phase power is calculated from the average median power in the period $t_{0}-16 \mathrm{~min}$ to $t_{0}-8 \mathrm{~min}$. The recovery phase power is calculated from the average median power in the period $t_{0}+8 \mathrm{~min}$ to $t_{0}+16 \mathrm{~min}$.

[22] In this paper, we seek to study the evolution of ULF wave power and compare it with the activation time of nightside aurora as a first step toward understanding the link between magnetic and optical onset. We use an independent estimate of the onset of auroral activity during substorms made available by Nishimura et al. [2010] in order to objectively investigate the evolution and growth of ULF wave activity as a function of frequency, latitude and epoch time, $t_{0}$. We use the Nishimura list to investigate any statistical difference between ULF wave activity during substorms and pseudo-breakups, at higher, onset and lower latitudes. It is noted by Nishimura et al. [2010] that the majority of these events are part of ongoing nightside geomagnetic activity - which we term compound events - and so we use an estimate of the local AL index in order to investigate the evolution of ULF wave activity in isolated and compound substorms and pseudo-breakups as a function of latitude away from auroral onset.

[23] At auroral activation latitudes the ULF wave power in all three wave bands ( $\mathrm{Pi} 1 *$, $\mathrm{Pi} 1-2$ and $\mathrm{Pi} 2$ ) is approximately constant before a pseudo-breakup or substorm, and approximately constant after a pseudo-breakup or substorm, although at an increased level. This implies that residual ULF wave power is observed for tens of minutes following an auroral activation. This may be a signature of the formation of the SCW via bouncing Alfvén waves [Lester et al., 1983], a series of directly driven ULF wave oscillations [Kepko and Kivelson, 1999], a Field Line Resonant structure [Rae et al., 2007], waves generated by the source of both auroral precipitation and BBFs (K. R. Murphy et al., A statistical analysis of ULF wave characteristics at substorm expansion phase onset, submitted to Annales Geophysicae, 2010), or indeed weak auroral activity in the recovery phase similar to the correlation between weak auroral fluctuations and ULF wave activity prior to substorm breakup as demonstrated by Rae et al. [2009a]. There is also an increase in ULF wave power at stations separated in latitude from the onset station in most wave bands. This increased wave power persists for tens of minutes after the auroral activation. Therefore the residual ULF wave power is not confined to the same latitude as the auroral activation. Interestingly, Newell et al. [2010] present clear evidence that the class of auroral precipitation which is associated with Alfven waves is significantly enhanced at (or indeed slightly prior to) auroral onset and persists for 10-15 min following onset. The results in this paper demonstrate that ULF wave power can be enhanced for at least $15 \mathrm{~min}$ following auroral onset. Using a self-consistent simulation, Watt and Rankin [2010] show that both the amount and energy of wave-accelerated auroral electrons is increased as the shear Alfvén wave amplitude increases, and that this acceleration could easily occur in the warm plasma of the plasma sheet as opposed to the traditional acceleration region directly above the auroral zone. This explanation provides a strong link between the observational results contained within this paper and the results of Newell et al. [2010].

[24] The increase in ULF wave power during a substorm is larger than during pseudo-breakups, for all ULF wave frequencies at auroral onset latitudes (cf. Figure 4 and Table 1) and at all latitudes (cf. Figure 6). Both the maximum ULF wave power and the residual recovery phase power are larger for substorms than for pseudo-breakups. There are few agreed differences between pseudo-breakups and substorms. Indeed, Aikio et al. [1999] presented comprehensive studies of the ionospheric, geosynchronous and midtail features of a series of pseudo-breakups and substorm expansion phase onsets, and concluded that there was no qualitative distinction between pseudo-breakups and substorm onsets, rather there is a continuum of states between these two classifications. One difference that is generally agreed upon is that pseudo-breakups are observed as localized auroral brightenings without significant poleward expansion, whereas substorms expand poleward toward and usually through the open-closed field line boundary. Thus substorms are able to harness the lobe flux, presumably via reconnection at the NENL [e.g., Baumjohann et al., 1996]. However, ULF wave activity in the Pil-2 period band has been shown to occur both concurrently and contemporaneously with the activations during both pseudo-breakups and substorms [e.g., Rae et al., 2009a]. The fact that ULF waves have higher amplitudes following substorms compared to pseudo-breakups is consistent with the Aikio et al. [1999] scenario whereby both substorms and pseudo-breakups are part of a continuum of activity, at least geomagnetically. It is also interesting that the ULF wave power is seen to increase at high latitudes for all events including pseudo-breakups, even though the auroral brightening is localized.

[25] ULF wave power is shown to increase before the independently defined auroral initiation noted in the Nishimura list across all ULF wave bands, event categories and latitudes. The recent work outlined by Murphy et al. [2009a, 2009b] and Rae et al. [2009a, 2009b, 2010] demonstrates clearly that for isolated substorms and pseudo-breakups, Pi1-2 ULF wave onset can be colocated in both time and space with the onset of small-scale auroral fluctuations along the substorm onset arc, which may be tens of seconds prior to the exponential increase in auroral arc luminosity presumably used by Nishimura et al. [2010] to define auroral onset. Nevertheless, it is extremely useful to be able to benchmark increases in ULF wave power against an independently derived onset time. There appears to be a time delay of ULF wave power increase at low latitudes (Figure 6) compared to auroral onset latitudes. Clearly, more 


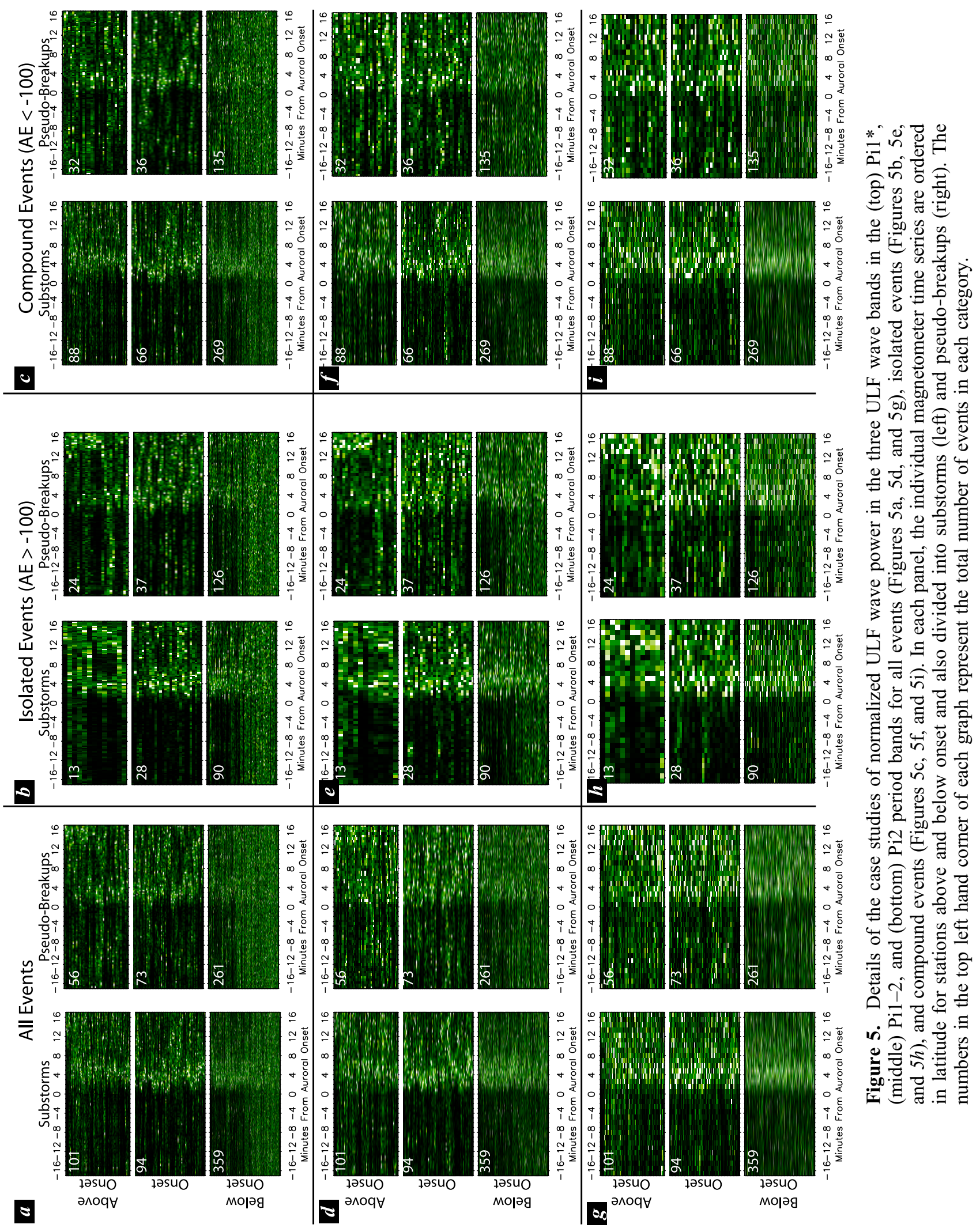



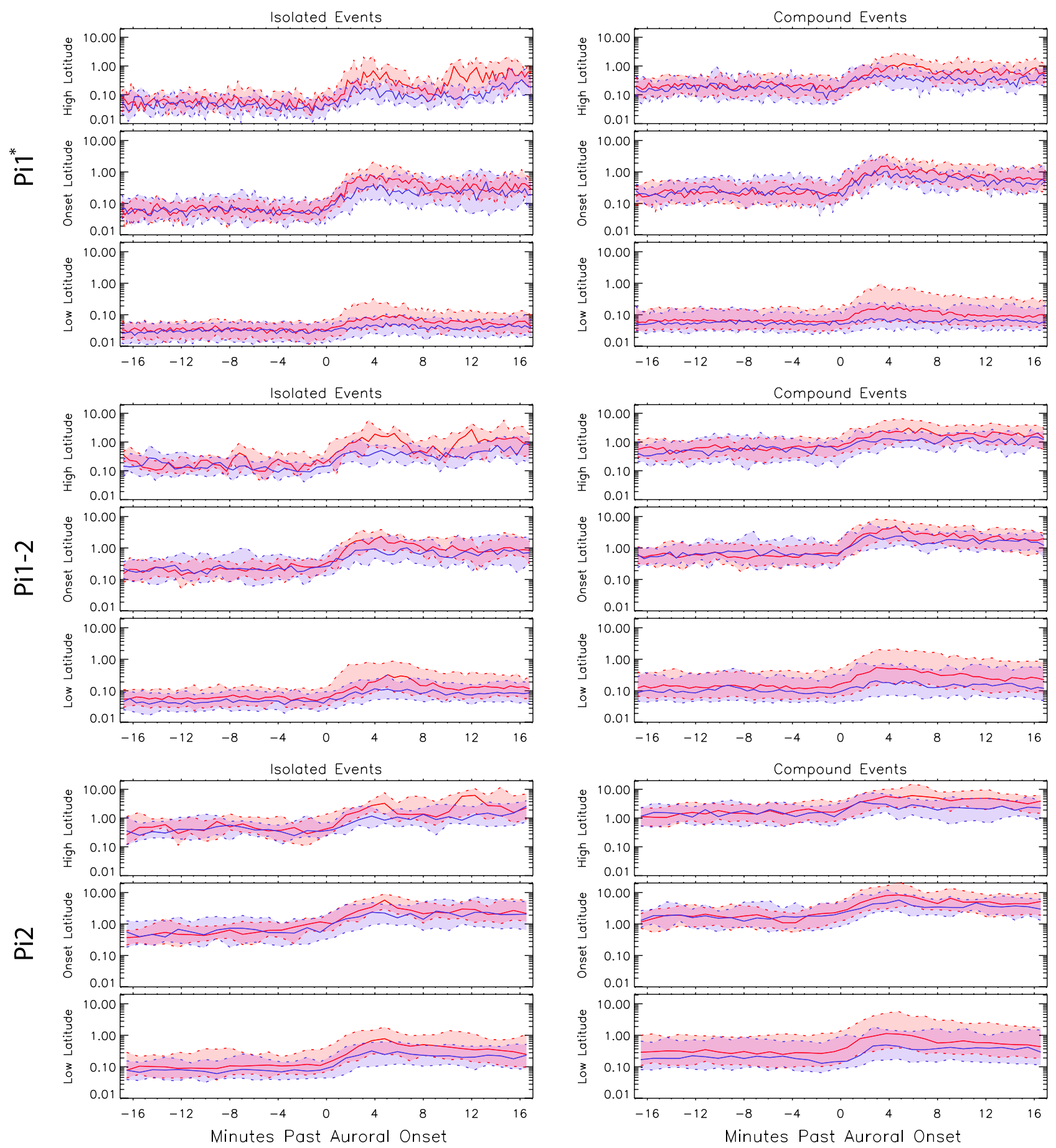

Figure 6. The median, upper and lower quartiles for substorms (in red) and pseudo-breakups (in blue) for (top) Pi1*, (middle) Pi1-2, and (bottom) Pi2 wave bands. The left panels are statistics for isolated events, and the right panels are the equivalent statistics for compound events. These median statistics are derived using the information shown in Figure 5.

work is required in order to investigate the relative growth of ULF wave onset at high, auroral onset and low latitudes on a case-by-case basis, rather than statistically.

[26] In general, the time of maximum ULF wave power is observed after $\mathrm{t}_{0}$, both statistically and for the majority of events as seen in the matrix plot (Figure 6). Liou et al. [2000] presented statistics of the onset time of Pi2 pulsations (defined by Liou et al. [2000] as the time of maximum wave amplitude minus $1 / 4$ wave period) at very low latitudes $(\mathrm{L}=1.07)$, and found that auroral breakup occurred prior to the observed maximum amplitudes by $2-3 \mathrm{~min}$. This result is consistent with the results contained within Table 1. However, as is clearly shown throughout this paper, ULF wave growth occurs prior to auroral breakup, consistent with the case studies shown by Murphy et al. [2009a, 
2009b], Rae et al. [2009a, 2009b, 2010], and Walsh et al. [2010].

[27] A number of studies have proposed that Pi2 ULF waves are a global mode [e.g., Olson, 1999 and references therein], while Pi1Bs specifically are localized to the substorm onset region [e.g., Bösinger and Yahnin, 1987; Posch et al., 2007]. For individual case studies, it has been shown that Pi1-2 ULF waves offer an excellent compromise between these two ULF wave extremes for the study of substorm expansion phase onset. Previous studies [e.g., Milling et al., 2008; Mann et al., 2008; Murphy et al., 2009a, 2009b; Rae et al., 2009a, 2009b, 2010] have shown that Pi1-2 ULF waves accurately define the location and time of auroral expansion phase onset, but are also observed at distances away from the onset region, giving scientists the opportunity to characterize the evolution of substorm disturbances in the ionosphere. Paper 1 presents a complementary statistical study of the spatial distribution of power and polarization of ULF waves in the Pi1*, Pi1-2 and Pi2 period bands during substorm expansion phase onset. These results of Paper 1 demonstrate that ULF waves obey a power law like power spectrum in frequency space during a forty minute window surrounding the onset process. Thus, Pi2 ULF waves have a larger amplitude than Pi1-2 ULF waves, which in turn have a larger amplitude than Pi1* ULF waves. In this paper, we demonstrate that a power law like dependence exists at all times during the temporal evolution of wave power during both substorms and pseudo-breakups, i.e., ULF wave power is always inversely related to wave frequency. The results in this paper conclusively demonstrate that all three wave bands, $\mathrm{Pi} 1 *$, $\mathrm{Pi} 1-2$ and $\mathrm{Pi} 2$, evolve in the same way during sudden auroral activations, whether they are substorms or pseudo-breakups. It does not seem as if $\mathrm{Pi} 2$ waves represent a different physical process to Pi1-2 waves or Pi $1 *$ waves, they are all part of the same continuum.

[28] Note that the exception to the above rule is for Pi1* waves at the lowest latitudes shown in Figure 6. Pi1* fluctuations do not register a significant increase in power between preonset and postonset during pseudo-breakups. Two potential reasons for this are that Pi1* power may not physically be observed at the lowest latitudes during pseudo-breakups and/or that the amplitudes of Pi1* waves at low latitudes are close to the noise floor of the fluxgate magnetometers used in this study. Of further note is that the initial ULF power level for each wave band is smaller at lower latitudes than it is at higher latitudes. Future work will involve performing the same analysis using data from the newly deployed CARISMA searchcoil magnetometer network [Mann et al., 2008] in order to investigate whether instrument sensitivity is a major factor in observing Pil ULF waves at large distances from auroral onset.

[29] The median ULF wave statistics shown in Figure 6 demonstrate that there is an interesting secondary ULF wave source at high latitudes some 8-12 min following auroral onset during isolated substorms, most notably in the Pi1* and Pi1-2 ULF wave bands, although it must be stated that this category contains the least number of events. However, the enhancement in high-latitude ULF wave power can also be seen in a number of the case studies shown in Figures $5 \mathrm{~b}, 5 \mathrm{e}$, and $5 \mathrm{~h}$. Whether this secondary power peak is due to the delayed expansion of ULF wave activity to higher latitudes during isolated substorms, or whether this corresponds to a secondary higher-latitude activation is not clear from this study, and will not be resolved using our isolated/compound criteria for activity levels prior to $t_{0}$. For example, the post expansion phase auroral oval exhibits a "double-oval" configuration, whereby activations at the poleward edge (e.g., PBIs [Lyons et al., 1999]) may occur independently of activations on the more equatorial branch of the oval. On the other hand, Rae et al. [2009b] interpreted the onset of Pil-2 ULF waves in conjunction with auroral fluctuations along the onset arc as evidence of a near-Earth plasma instability initiating expansion phase onset, while the delayed higher-latitude auroral breakup signature was hypothesized to be associated with reconnection and energy release at the NENL, i.e., once outward propagating disturbances reached the NENL [e.g., Friedrich et al., 2001], reconnection would subsequently initiate auroral breakup $\sim$ minutes later. Regardless of interpretation, a secondary ULF wave power peak is observed at high latitudes 8-12 min following $t_{0}$.

[30] At first glance, it appears that the onset of wave growth at auroral latitudes occurs significantly earlier for longer-period ULF waves and prior to onset. This statistical result appears to be in conflict with the case study results of Milling et al. [2008], Murphy et al. [2009a, 2009b], Rae et al. [2009a, 2009b] and Walsh et al. [2010] who determined that Pi1-2 ULF waves occurred first in the localized epicenter of auroral onset. Note, however, that the uncertainty associated in determining ULF wave power using the AWESOME wavelet technique is also dependent on frequency range, for Pi1*, Pi1-2 and Pi2 ULF waves, the associated uncertainties are $\pm 8, \pm 16$ and $\pm 32 \mathrm{~s}$, respectively. Hence for the majority of events, the onset times of wave growth are consistent with previous results when allowing for the uncertainties in each wave band. However, it is most important to note that Figure 4 shows median ULF wave power relative to the onset time, $t_{0}$. The correct determination of the relative timing of specific ULF wave bands through auroral activations should be accomplished by separately calculating ULF wave onset times for each event and then analyzing the median values. This work will be contained within a future publication.

[31] Regardless, any model of substorm expansion phase onset reported in the literature must be able to explain the growth of ULF wave power at all frequencies $\sim$ minutes prior to auroral expansion phase onset. Models which predict that the ULF wave power to rise following an auroral brightening are shown here to be incorrect, or at the very least require significant modification, in order to fit these statistical results.

\section{Conclusions}

[32] In this paper, we present a statistical study of the evolution of ULF wave power during nightside auroral activations. We utilize the independently derived auroral activation list [Nishimura et al., 2010] to detail the time evolution of ULF wave power during the onset of substorms and pseudo-breakups. Data from magnetometer stations near to the auroral activation sites are used to determine whether there is any statistical difference between the time evolution of ULF wave power during substorms and pseudo-breakups at the latitude of auroral activation, and at higher and lower 
latitudes. We subsequently divide the list of events into isolated and compound activations in order to determine whether there is any significant difference between events that are part of ongoing nightside magnetic activity and isolated events that are not.

[33] From this study we find that:

[34] 1. ULF wave power is larger in the $\mathrm{Pi} 2$ band than the Pi1-2 band than the Pi1* band throughout all events. This is consistent with the results shown in Paper 1.

[35] 2. The evolution of ULF wave power in the Pi1*, Pi1-2 and Pi2 bands is essentially the same for all types of events; the differences are in the wave amplitudes, not in the temporal evolution of each wave mode. This implies that the categorization of these waves based on period bands is more of an artificial constraint than a physical one.

[36] 3. ULF wave power is approximately constant before auroral onset, and constant after auroral onset but at a higher level. This increase is seen at the auroral activation latitude and at higher and lower latitudes.

[37] 4. Increases in ULF wave power during a substorm are larger than during a pseudo-breakup.

[38] 5. ULF wave power prior to the onset of compound events is as large as the ULF wave power following onset in isolated events, implying that the enhanced ULF wave power observed before a compound event is due to the residual ULF wave power that persists after a previous auroral activation.

[39] 6. ULF wave power increases before auroral onset in all ULF wave bands as defined in the Nishimura list, while maximum ULF wave amplitudes clearly occur after auroral onset.

[40] 7. There is evidence of a secondary ULF wave activation at higher latitudes $\sim 10$ min following auroral onset.

[41] In summary, we use the statistical database of auroral onsets given by Nishimura et al. [2010] to determine the time evolution of ULF wave power as a function of epoch time, latitude and frequency. These results have important consequences for models of expansion phase onset.

[42] Acknowledgments. I.J.R. and C.E.J.W. are funded by the CSA. K.R.M. is funded by NSERC-CGSD and Alberta Ingenuity scholarships. CARISMA is operated by the University of Alberta, funded by the CSA THEMIS is funded by NASA contract NAS5-02099. The authors thank NRCan for the provision of data from the Canadian Magnetic Observatory System (CANMOS) Network, C. T. Russell for THEMIS GMAG data, and M. Engebretson for MACCS data. The authors would like to thank H. Bateup and M. McGahey for the visual concept of Figures 1,2,3, and 5.

[43] Robert Lysak thanks the reviewers for their assistance in evaluating this paper.

\section{References}

Aikio, A. T., V. A. Sergeev, M. A. Shukhtina, L. I. Vagina, V. Angelopoulos, and G. D. Reeves (1999), Characteristics of pseudobreakups and substorms observed in the ionosphere, at the geosynchronous orbit, and in the midtail, J. Geophys. Res., 104(A6), 12,263-12,287, doi:10.1029/ 1999JA900118.

Akasofu, S. I. (1964), The development of the auroral substorm, Planet. Space Sci., 12(4), 273-282, doi:10.1016/0032-0633(64)90151-5.

Angelopoulos, V. (2008), The THEMIS Mission, Space Sci. Rev., 141(1-4), 5-34, doi:10.1007/s11214-008-9336-1.

Angelopoulos, V., et al. (2008a), First results from the THEMIS mission, Space Sci. Rev., 141(1-4), 453-476, doi:10.1007/s11214-008-9378-4.

Angelopoulos, V., et al. (2008b), Tail reconnection triggering substorm onset, Science, 321(5891), 931-935, doi:10.1126/science.1160495.
Angelopoulos, V., et al. (2009), Response to Comment on "Tail reconnection triggering substorm onset," Science, 324(5933), 1391, doi:10.1126/ science. 1168045

Arnoldy, R. L., R. Rajashekar, L. J. Cahill, M. J. Engebretson, T. J. Rosenberg, and S. B. Mende (1987), Simultaneous measurement of aurora-related, irregular magnetic pulsations at northern and southern high-latitudes, J. Geophys. Res., 92(A11), 12,221-12,232, doi:10.1029/JA092iA11p12221.

Arnoldy, R. L., J. L. Posch, M. J. Ebgebretson, H. Fukunishi, and H. J. Singer (1998), Pi1 magnetic pulsations in space and at high latitudes on the ground, J. Geophys. Res., 103(A10), 23,581-23,591, doi:10.1029/98JA01917.

Baumjohann, W., and K. H. Glassmeier (1984), The transient-response mechanism and Pi2 pulsations at substorm onset- Review and outlook, Planet. Space Sci., 32(11), 1361-1370, doi:10.1016/0032-0633(84) 90079-5.

Baumjohann, W., Y. Kamide, and R. Nakamura (1996), Substorms, storms, and the near-Earth tail, J. Geomag. Geoelectr., 48(2), 177-185.

Bösinger, T. (1989), On the spectral index of the Pilb power spectrum, Ann. Geophys., 7(4), 375-386.

Bösinger, T., and A. G. Yahnin (1987), Pi1b type magnetic pulsation as a high time resolution monitor of substorm development, Ann. Geophys., Ser. A, 5(4), 231-237.

Cheng, C. Z. (2004), Physics of substorm growth phase, onset, and depolarization, Space Sci. Rev., 113(1-2), 207-270, doi:10.1023/B: SPAC.0000042943.59976.0e

Elphinstone, R. D., et al. (1995), Observations in the vicinity of substorm onset: Implications for the substorm process, J. Geophys. Res., 100(A5), 7937-7969, doi:10.1029/94JA02938

Frey, H. U., and S. B. Mende (2007), Substorm onsets as observed by IMAGE-FUV, in Proceedings of the Eighth International Conference on Substorms, edited by M. T. Syrjäsuo and E. Donovan, pp. 71-75, Univ. of Calgary, Alberta, Canada.

Frey, H. U., S. B. Mende, V. Angelopoulos, and E. F. Donovan (2004), Substorm onset observations by IMAGE-FUV, J. Geophys. Res., 109 A10304, doi:10.1029/2004JA010607.

Friedrich, E., J. C. Samson, I. Voronkov, and G. Rostoker (2001), Dynamics of the substorm expansive phase, J. Geophys. Res., 106(A7), 13,14513,163, doi:10.1029/2000JA000292.

Gelpi, C., H. J. Singer, and W. J. Hughes (1987), A comparison of magnetic signatures and DMSP auroral images at substorm onset: Three case studies, J. Geophys. Res., 92(A3), 2447-2460, doi:10.1029/ JA092iA03p02447.

Heppner, J. P. (1958), A study of the relationships between the aurora borealis and the geomagnetic disturbances caused by electric currents in the ionosphere, Ph.D. dissertation, Calif. Instit. of Technol., Pasadena.

Hones, E. W. (1976), Observations in Earth's magnetotail relating to magnetic merging, Sol. Phys., 47(1), 101-113, doi:10.1007/BF00152248.

Horton, W., H. V. Wong, J. W. Van Dam, and C. Crabtree (2001), Stability properties of high-pressure geotail flux tubes, J. Geophys. Res., 106(A9), 18,803-18,822, doi:10.1029/2000JA000415.

Jacobs, J. A., S. Matsushita, Y. Kato, and V. A. Troitskaya (1964), Classification of geomagnetic micropulsations, J. Geophys. Res., 69(1), 180-181, doi:10.1029/JZ069i001p00180.

Keiling, A. (2009), Alfvén waves and their roles in the dynamics of the Earth's magnetotail: A review, Space Sci. Rev., 142(1-4), 73-156, doi:10.1007/s11214-008-9463-8.

Kepko, L., and M. Kivelson (1999), Generation of Pi2 pulsations by bursty bulk flows, J. Geophys. Res., 104(A11), 25,021-25,034, doi:10.1029/ 1999JA900361.

Lessard, M. R., E. J. Lund, S. L. Jones, R. L. Arnoldy, J. L. Posch, M. J. Engebretson, and K. Hayashi (2006), Nature of Pi1B pulsations as inferred from ground and satellite observations, Geophys. Res. Lett. 33, L14108, doi:10.1029/2006GL026411.

Lester, M., W. J. Hughes, and H. J. Singer (1983), Polarization patterns of Pi 2 magnetic pulsations and the substorm current wedge, J. Geophys. Res., 88(A10), 7958-7966, doi:10.1029/JA088iA10p07958.

Liou, K., and Y.-L. Zhang (2009), Comment on "Wavelet-based ULF wave diagnosis of substorm expansion phase onset" by K. Murphy et al., J. Geophys. Res., 114, A10206, doi:10.1029/2009JA014207.

Liou, K., C. I. Meng, P. T. Newell, K. Takahashi, S. I. Ohtani, A. T. Y. Lui, M. Brittnacher, and G. Parks (2000), Evaluation of low-latitude Pi2 pulsations as indicators of substorm onset using Polar ultraviolet imagery, J. Geophys. Res., 105(A2), 2495-2505, doi:10.1029/1999JA900416.

Lui, A. T. Y. (2004), Potential plasma instabilities for substorm expansion onsets, Space Sci. Rev., 113(1-2), 127-206, doi:10.1023/B: SPAC.0000042942.00362.4e

Lui, A. T. Y. (2009), Comment on "Tail reconnection triggering substorm onset," Science, 324(5933), doi:10.1126/science.1167726. 
Lui, A. T. Y., C. L. Chang, A. Mankofsky, H. K. Wong, and D. Winske (1991), A cross-field current instability for substorm expansions, J. Geophys. Res., 96(A7), 11,389-11,401, doi:10.1029/91JA00892.

Lyons, L. R., T. Nagai, G. T. Blanchard, J. C. Samson, T. Yamamoto, T. Mukai, A. Nishida, and S. Kokubun (1999), Association between Geotail plasma flows and auroral poleward boundary intensifications observed by CANOPUS photometers, J. Geophys. Res., 104(A3), 4485-4500, doi:10.1029/1998JA900140.

Mann, I. R., et al. (2008), The upgraded CARISMA magnetometer array in the THEMIS era, Space Sci. Rev., 141(1-4), 413-451, doi:10.1007/ s11214-008-9457-6.

Maynard, N. C., W. J. Burke, E. M. Basinska, G. M. Erickson, W. J. Hughes, H. J. Singer, A. G. Yahnin, D. A. Hardy, and F. S. Mozer (1996a), Dynamics of the inner magnetosphere near times of substorm onsets, J. Geophys. Res., 101(A4), 7705-7736, doi:10.1029/95JA03856.

Maynard, N. C., W. J. Burke, G. M. Erickson, E. M. Basinska, and A. G. Yahnin (1996b), Magnetosphere-ionosphere coupling during substorm onset, in Proceedings of the Third International Conference on Substorms, edited by E. J. Rolfe and B. Kaldeich, pp. 301-305, Eur. Space Agency, Paris.

McPherron, R. L., C. W. Arthur, M. D. Bossen, and C. T. Russell (1973), Micropulsation substorm at synchronous orbit Ats-1 observations of ULF waves, Eos Trans. AGU, 54(4), 420.

Milling, D. K., I. J. Rae, I. R. Mann, K. R. Murphy, A. Kale, C. T. Russell, V. Angelopoulos, and S. Mende (2008), Ionospheric localization and expansion of long-period Pil pulsations at substorm onset, Geophys Res. Lett., 35, L17S20, doi:10.1029/2008GL033672.

Murphy, K. R., I. J. Rae, I. R. Mann, D. K. Milling, C. E. J. Watt, L. Ozeke, H. U. Frey, V. Angelopoulos, and C. T. Russell (2009a), Wavelet-based ULF wave diagnosis of substorm expansion phase onset, J. Geophys. Res., 114, A00C16, doi:10.1029/2008JA013548.

Murphy, K. R., I. J. Rae, I. R. Mann, A. P. Walsh, D. K. Milling, C. E. J. Watt, L. Ozeke, H. U. Frey, V. Angelopoulos, and C. T. Russell (2009b), Reply to comment by K. Liou and Y.-L. Zhang on "Wavelet-based ULF wave diagnosis of substorm expansion phase onset," J. Geophys. Res., 114, A10207, doi:10.1029/2009JA014351

Murphy, K. R., I. J. Rae, I. R. Mann, and D. K. Milling (2011), On the nature of ULF wave power during nightside auroral activations and substorms: 1. Spatial distribution, J. Geophys. Res., 116, A00I21, doi:10.1029/2010JA015757.

Newell, P. T., A. R. Lee, K. Liou, S. I. Ohtani, T. Sotirellis, and S. Wing (2010), Substorm cycle dependence of various types of aurora, J. Geophys. Res., 115, A09226, doi:10.1029/2010JA015331.

Nishimura, Y., L. R. Lyons, S. Zou, V. Angelopoulos, and S. Mende (2010), Substorm triggering by new plasma intrusion: THEMIS all-sky imager observations, J. Geophys. Res., 115, A07222, doi:10.1029/ 2009JA015166.

Ohtani, S. I. (2004), Flow bursts in the plasma sheet and auroral substorm onset: Observational constraints on connection between midtail and nearEarth substorm processes, Space Sci. Rev., 113(1-2), 77-96, doi:10.1023/B:SPAC.0000042940.59358.2f.

Olson, J. V. (1999), Pi2 pulsations and substorm onsets: A review, J. Geophys. Res., 104(A8), 17,499-17,520.

Olson, J. V., and G. Rostoker (1975), Pi 2 pulsations and the auroral electrojet, Planet. Space Sci., 23, 1129-1139, doi:10.1016/0032-0633(75) 90163-4.

Peticolas, L. M., et al. (2008), The time history of events and macroscale interactions during substorms (THEMIS) education and public outreach program, Space Sci. Rev., 141(1-4), 557-583, doi:10.1007/s11214008-9458-5.
Posch, J. L., M. J. Engebretson, S. B. Mende, H. U. Frey, R. L. Arnoldy, M. R. Lessard, L. J. Lanzerotti, J. Watermann, M. B. Moldwin, and P. V. Ponomarenko (2007), Statistical observations of spatial characteristics of Pi1B pulsations, J. Atmos. Sol. Terr. Phys., 69(15), 1775-1796, doi:10.1016/j.jastp.2007.07.015.

Rae, I. J., I. R. Mann, D. K. Milling, Z. C. Dent, and A. Kale (2007), Pi2 pulsations: Field line resonances or a driven response?, in Proceedings of the Eighth International Conference on Substorms, edited by M. T. Syrjäsuo and E. Donovan, pp. 253-258, Univ. of Calgary, Alberta, Canada.

Rae, I. J., et al. (2009a), Timing and localization of ionospheric signatures associated with substorm expansion phase onset, J. Geophys. Res., 114, A00C09, doi:10.1029/2008JA013559.

Rae, I. J., et al. (2009b), Near-Earth initiation of a terrestrial substorm, J. Geophys. Res., 114, A07220, doi:10.1029/2008JA013771.

Rae, I. J., C. E. J. Watt, I. R. Mann, K. R. Murphy, J. C. Samson, K. Kabin, and V. Angelopoulos (2010), Optical characterization of the growth and spatial structure of a substorm onset arc, J. Geophys. Res., 115, A10222, doi:10.1029/2010JA015376.

Rostoker, G., and T. Eastman (1987), A boundary-layer model for magnetospheric substorms, J. Geophys. Res., 92(A11), 12,187-12,201, doi:10.1029/JA092iA11p12187.

Roux, A., S. Perraut, P. Robert, A. Morane, A. Pedersen, A. Korth, G. Kremser, B. Aparicio, D. Rodgers, and R. Pellinen (1991), Plasma sheet instability related to the westward traveling surge, J. Geophys. Res., 96(A10), 17,697-17,714, doi:10.1029/91JA01106.

Russell, C. T., P. J. Chi, D. J. Dearborn, Y. S. Ge, B. Kuo-Tiong, J. D. Means, D. R. Pierce, K. M. Rowe, and R. C. Snare (2008), THEMIS ground-based magnetometers, Space Sci. Rev., 141(1-4), 389-412, doi:10.1007/s11214-008-9337-0.

Samson, J. C. (1985), Large scale studies of Pi 2's associated with auroral breakups, J. Geophys., 56, 133-145.

Song, Y., and R. L. Lysak (2001), Towards a new paradigm: From a quasisteady description to a dynamical description of the magnetosphere, Space Sci. Rev., 95(1-2), 273-292, doi:10.1023/A:1005288420253.

Southwood, D. J., and W. J. Hughes (1985), Concerning the structure of Pi 2 pulsations, J. Geophys. Res., 90(A1), 386-392, doi:10.1029/ JA090iA01p00386.

Takahashi, K., and K. Liou (2004), Longitudinal structure of low-latitude Pi2 pulsations and its dependence on aurora, J. Geophys. Res., 109 A12206, doi:10.1029/2004JA010580.

Voronkov, I., R. Rankin, P. Frycz, V. T. Tikhonchuk, and J. C. Samson (1997), Coupling of shear flow and pressure gradient instabilities, J. Geophys. Res., 102(A5), 9639-9650, doi:10.1029/97JA00386.

Walsh, A. P., et al. (2009), Cluster and Double Star multipoint observations of a plasma bubble, Ann. Geophys., 27(2), 725-743, doi:10.5194/angeo27-725-2009.

Walsh, A. P., et al. (2010), Comprehensive ground-based and in-situ observations of substorm expansion phase onset, J. Geophys. Res., 115, A00I13, doi:10.1029/2010JA015748.

Watt, C. E. J., and R. Rankin (2010), Do magnetospheric shear Alfvén waves generate sufficient electron energy flux to power the aurora?, J. Geophys. Res., 115, A07224, doi:10.1029/2009JA015185.

I. R. Mann, K. R. Murphy, I. J. Rae, and C. E. J. Watt, Department of Physics, University of Alberta, Edmonton, AB T6G 2J1, Canada. (jonathan.rae@ualberta.ca) 